\title{
Determination of Total Arsenic in Seaweed Products by Neutron Activation Analysis
}

\author{
N. Salim ${ }^{1,2^{*}}$, M. Santoso ${ }^{3}$, S. Damayanti ${ }^{1}$ and T.G. Kartawinata ${ }^{1}$ \\ ${ }^{I}$ School of Pharmacy, Bandung Institute of Technology \\ Jl. Ganesha 10, Bandung 40132, Indonesia \\ ${ }^{2}$ Jabatan Farmasi, Hospital Sultanah Nora Ismail, \\ Jl. Korma 83000 Batu Pahat, Johor, Malaysia \\ ${ }^{3}$ Center for Nuclear Technology of Material and Radiometry, National Nuclear Energy Agency \\ Jl. Tamansari 71, Bandung 40132, Indonesia
}

\section{ARTICLE INFO}

\section{Article history:}

Received 16 January 2013

Received in revised form 11 April 2013

Accepted 13 April 2013

Keywords:

Seaweed

Arsenic

Neutron activation analysis

Consumer exposure

\begin{abstract}
A B S T R A C T
Seaweed products are widely consumed as food nowadays. Seaweeds are known to contain arsenic due to their capability to accumulate arsenic from the environment. Arsenic is a known toxic element which naturally occurs in the environment. Ingestion of high levels of arsenic will cause several adverse health effects. Arsenic in food occurs at trace concentrations which require sensitive and selective analysis methods to perform elemental analysis on. Validated neutron activation analysis was used to determine the arsenic contents in seaweed products namely catoni from domestic product and nori from foreign products. The total arsenic concentration in the samples analyzed ranges from $0.79 \mathrm{mg} / \mathrm{kg}$ to $30.14 \mathrm{mg} / \mathrm{kg}$ with mean concentration $14.39 \mathrm{mg} / \mathrm{kg}$. The estimated exposure to arsenic contributed by the analyzed products is from $0.07 \%$ up to $8.54 \%$ of the established provisional tolerable daily intake (PTDI) which is still far below the maximum tolerable level.
\end{abstract}

C) 2013 Atom Indonesia. All rights reserved

\section{INTRODUCTION}

The seaweed is an increasingly popular food nowadays. Besides being used as food, it also utilised in soil manure, salt extractions, colloid production, cosmetics, pharmaceuticals, and energy production [1]. In the Far East seaweed is mostly incorporated into the daily diet. It is used dried in condiment and soup bases or eaten fresh in salads, rolls, or stews, or with rice [2]. Edible seaweed is a good source of iodine [2], polysaccharides and proteins [3].

Arsenic (As) is an environmental contaminant. It can arise both from natural sources, such as rocks and sediments, and as a result of human activities such as coal burning, copper smelting, and processing of mineral ores [4]. Arsenic can exist in inorganic and organic compounds. Both organic and inorganic arsenic are readily absorbed by the gastrointestinal tract $[5,6]$. The complex organic arsenic compounds are much less acutely toxic than soluble inorganic compounds [7].

Arsenic is genotoxic and is a known human carcinogen $[5,8,9]$ associated especially with liver, bladder, lung and skin cancer. Following oral

\footnotetext{
* Corresponding author.

E-mail address: ain_mas2@yahoo.com
}

exposures of arsenic, gastrointestinal irritation, pancytopenia, hepatic injury and neuropathy can occur $[6,8]$. Nausea, vomiting, and diarrhea are very common symptoms in humans following oral exposures to inorganic arsenicals due to a direct irritation of the gastrointestinal mucosa. Acute, high-dose exposure can lead to encephalopathy, with clinical signs such as confusion, hallucinations, impaired memory, and emotional lability. Long-term exposure to lower levels can lead to the development of peripheral neuropathy characterized by numbness in the hands and feet up to a painful sensation. Neurobehavioral alterations have also been observed in arsenic-exposed children [8].

Seaweeds are known to contain higher concentrations of arsenic in comparison to terrestrial plants as marine plants are able to concentrate the arsenic derived from sea water. Certain seaweeds do not perform the metabolic conversion process found in fish or mammals and deposit the arsenic in a range of chemical forms, including significant proportions as the toxic inorganic forms, As(III) and As(V) [9]. Several suggested reasons for this inorganic arsenic deposition include the lack of the requisite genetic capability, the excessive energetic costs of the metabolic transformation, and the use of stored of inorganic arsenic within the cellular structure as a form of protection against predation [10]. 
Arsenic in foodstuffs generally occurs in low concentrations; hence, a highly sensitive analytical technique is needed for the analysis of arsenic in foodstuffs. The neutron activation analysis (NAA) is an analytical method with the high sensitivity and selectivity needed for trace element analysis. NAA offers easy sample preparation, freedom of reagent blanks, minimum interferences, and rare matrix effect. NAA method is relatively free from reagent and laboratory contamination and is also capable of simultaneous multi-element analysis [11].

The Joint Food and Agricultural Organization/World Health Organization (FAO/WHO) Expert Committee on Food Additives (JECFA) has established the provisional tolerable daily intake (PTDI) of total arsenic as $50 \mu \mathrm{g} / \mathrm{kg}$ body weight (bw) per day. Concerning the toxicity of inorganic arsenic, the committee established the provisional tolerable weekly intake (PTWI) for inorganic arsenic as $15 \mu \mathrm{g} / \mathrm{kg}$ bw [12].

The purpose of this research was to determine the total arsenic concentration in seaweed food products by using neutron activation analysis. This method is expected to be an alternative analytical method for arsenic analysis in food stuffs.

\section{THEORY}

The neutron activation analysis is an analytical technique which is based on the measurement of characteristic gamma $(\gamma)$-rays emitted by analyte isotopes produced by irradiation with neutrons. The type of NAA commonly used is the instrumental NAA (INAA), in which there is no chemical treatment done to the samples prior or after its irradiation. The normal reaction which occurs in NAA is the neutron capture reaction. For most applications, it is the delayed $\gamma$ radiation from the radioactive product which is detected after activation [13]. Fig. 1 shows the scheme of the neutron activation analysis.

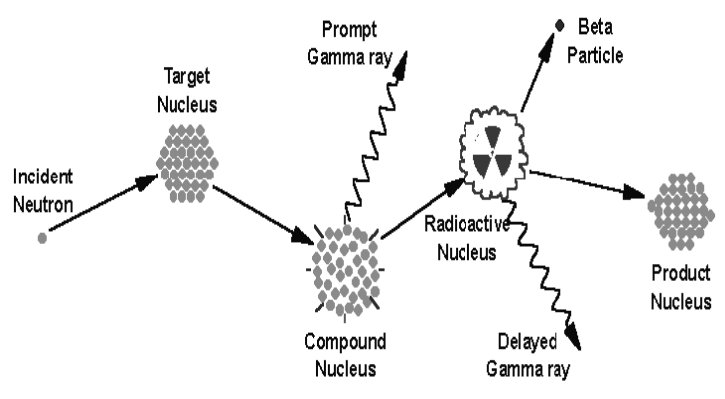

Fig. 1. Scheme of neutron activation analysis.

The activity of a nuclide can be determined by using the equation

$$
A_{0}=\frac{N_{c} \lambda e^{\lambda t} D}{\left(1-e^{-\lambda t} c\right)}
$$

where $N_{c}$ is the net peak count, $\lambda$ is the decay constant, $t_{D}$ is the time difference between time after irradiation and the time when counting is started, and $t_{c}$ is the counting time [14]. To use this equation, the absolute activity of the irradiated sample has to be measured. For convenience, the comparator method is often used in NAA where samples and comparator standards containing known amount of analyte are irradiated simultaneously.

In this method it is assumed that the neutron flux, cross sections, irradiation times and other variables associated with counting are constant for both the sample and the standard [11]. The total arsenic concentration in the sample can be calculated using the formula

$$
W_{\text {sample }}=W_{\text {std }} \times \frac{A_{\text {sample }}}{A_{\text {std }}}
$$

where $W_{\text {sample }}$ is the mass of arsenic in sample, $W_{\text {std }}$ is the mass of arsenic in standard, $A_{\text {sample }}$ is the activity of the sample and $A_{\text {std }}$ is the activity of a standard with known concentration of arsenic.

\section{EXPERIMENTAL METHODS}

\section{Sampling and sample preparation}

Samples analyzed were of catoni and nori types. The samples were purchased from 3 different markets for each type. The catoni products taken for analysis were from a domestic source (A) while the nori products were from foreign sources $(\mathrm{B}, \mathrm{C}$, $D, E)$. The samples were homogenized using food mixer. The nori which was sold as dry sheets was homogenized using food mill. For catoni which was sold as wet product, it was first weighed and put into tubes and frozen in the freezer. The samples were then freeze dried for 48 hours. Dried samples were powdered using a teflon mortar and pestle and placed into polyethylene container.

Each of the homogenized samples weighed $0.030 \mathrm{~g}$ and was put into $0.2 \mathrm{ml}$ polyethylene vials and heat sealed. Each sample was made a duplicate. The vials with samples were wrapped in aluminium foil and labelled with the respective sample codes.

\section{Comparator standards}

The elemental comparator standard for NAA was made from ICP-MS multi-element standard solution VI CertiPUR ${ }^{\circledR}$ (Merck). $100 \mu \mathrm{L}$ of this 
standard was pipetted into a $0.2 \mathrm{ml}$ polyethylene vial. Replicate standards were prepared and then dried under infrared lamps in the standard drying shelf. The vials were heat-sealed, wrapped in aluminium foil, and labelled.

\section{Standard reference material}

The NIST $1566 \mathrm{~b}$ oyster tissue standard reference material (SRM) was used for external quality assessment. $0.030 \mathrm{~g}$ SRM was weighed into vials and the vials were then heat-sealed, wrapped with aluminium foil, and labelled. Eight replicates were prepared.

\section{Irradiation and analysis}

The samples, the SRMs and the standards were grouped and irradiated using the rabbit system facility at the G.A Siwabessy reactor, Serpong, Jakarta for 15 minutes at $15 \mathrm{MW}$ power followed by cooling for 72 hours. Following the cooling of irradiated vials, the counting was done in the Centre of Nuclear Technology for Materials and Radiometry, Bandung, using a gamma-ray spectrophotometry system with an HPGe detector and Genie 2000 software. Dead time was ensured to be $20 \%$ and below for the counting. The samples, the comparator standards and the SRMs were counted at distance $10 \mathrm{~cm}$ from detector surface. Samples were counted for 3000 seconds. Gamma ray signal was counted at energy peak of $559.1 \mathrm{keV}$ (photopeak of ${ }^{76} \mathrm{As}$ ). The total arsenic contents in samples and SRMs were calculated using the comparison method.

\section{RESULTS AND DISCUSSION}

\section{Quality control assessment}

The reliability of the results obtained and the accuracy of the method of analysis in this research was assessed using SRM NIST 1566b Oyster tissue [15]. Eight replicates were analyzed. The validation data is shown in Table 1.

Table 1. Quality control assessment using NIST 1566b Oyster Tissue $(\mathrm{n}=8)$.

\begin{tabular}{cccc}
\hline $\begin{array}{c}\text { Certified } \\
\text { value }(\mathrm{mg} / \mathrm{kg})\end{array}$ & $\begin{array}{c}\text { Measured } \\
\text { value }(\mathrm{mg} / \mathrm{kg})\end{array}$ & $\begin{array}{c}\text { Average } \\
\text { Recovery }(\%)\end{array}$ & $\begin{array}{c}\text { Average } \\
\mathrm{CV}(\%)\end{array}$ \\
\hline $7.65 \pm 0.65$ & $7.81 \pm 0.87$ & 102.04 & 3.88 \\
\hline
\end{tabular}

The analytical accuracy, represented by the percentage of recovery, and the analytical precision, represented by the percentage of coefficient of variance $(\mathrm{CV})$, were found to be acceptable according to the Association of Analytical Communities (AOAC) guidelines [16].

The concentration of arsenic in the samples analyzed is shown in Table 2. Arsenic was detected in all samples. Catoni seaweed analyzed has the lowest arsenic content. This low concentration might be caused by the process undergone by the seaweed in the production. Washing and drying were done to the seaweed to remove sand and other particles. As the sample analyzed was used as condiment in cocktail and drinks, the seaweed was previously washed and bleached as to produce white colour and added with sugar and water and packed together with the seaweed. The arsenicals may have been leached out during these processes. Nori products from the foreign source $\mathrm{C}$ have the highest concentration of total arsenic. Processes such as roasting or toasting which are usually undertaken in nori production do not decrease the total arsenic concentration of the seaweed [17].

Table 2. Range of mean total arsenic concentration in the seaweed products analyzed.

\begin{tabular}{ccc}
\hline Sample & $\begin{array}{c}\text { Origin } \\
\text { products }\end{array}$ & $\begin{array}{c}\text { Total arsenic concentration } \\
(\mathrm{mg} / \mathrm{kg})^{*}\end{array}$ \\
\hline Catoni & Domestic & $0.86 \pm 0.05$ \\
& $(\mathrm{~A})$ & $(0.79 \pm 0.06-0.92 \pm 0.03)$ \\
Nori & Foreign & $17.20 \pm 0.95$ \\
& $(\mathrm{~B})$ & $(14.62 \pm 0.74-18.58 \pm 1.16)$ \\
& Foreign & $20.95 \pm 1.40$ \\
& (C) & $(16.05 \pm 0.28-30.14 \pm 1.61)$ \\
& Foreign & $20.15 \pm 2.00$ \\
& (D) & $(18.81 \pm 0.95-21.34 \pm 2.19)$ \\
& Foreign & $12.75 \pm 0.60$ \\
& (E) & $(10.24 \pm 0.28-15.12 \pm 0.45)$ \\
\hline
\end{tabular}

${ }^{*}$ Data are expressed as average concentration (range of mean concentration \pm standard deviation) $(\mathrm{mg} / \mathrm{kg}$ dry weight)

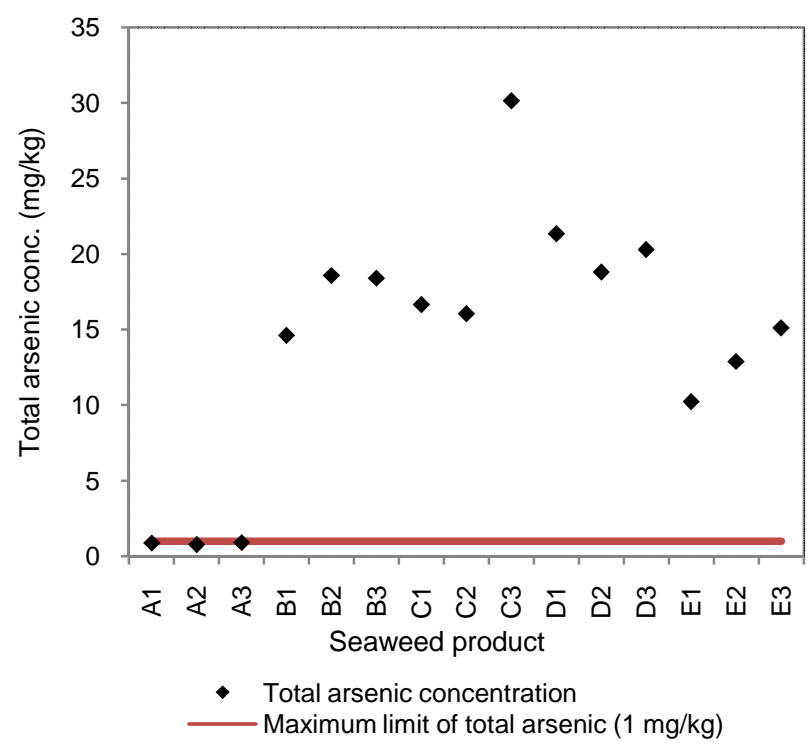

Fig. 2. Total arsenic concentration in seaweed products analyzed and the regulatory limit. 
The National Standardisation Agency of Indonesia has established a maximum limit for total arsenic concentration in seafood and other products of $1 \mathrm{mg} / \mathrm{kg}$ [18]. The comparison of the arsenic content in seaweed products analyzed to the amount permitted by the authority is shown in Fig. 2. Among all the samples analyzed, only catoni products contain the total arsenic concentration of less than $1 \mathrm{mg} / \mathrm{kg}$ while other products exceed the regulatory limit.

The PTDI for total arsenic set by JECFA is $0.05 \mathrm{mg} / \mathrm{kg}$ bw per day [19]. As there were concerns regarding the toxicity of inorganic arsenic, the exposure to inorganic arsenic was also assessed. It has been reported that inorganic arsenic accounts for $3.3 \%$ of total arsenic in seaweed [19]. Thus, the inorganic arsenic contents in the seaweed samples can be deduced by multiplying the mean ratio value of $3.3 \%$ with the concentration of total arsenic found in those samples. The estimated inorganic arsenic concentrations in the samples are shown in Table 3.

The consumer exposure to arsenic from food intake can be estimated from the average consumption of the food by the population. However in Indonesia there was no data on the average daily consumption of seaweed by the population. The average per capita daily consumption by Korean population was $8.5 \mathrm{~g}$ $[20,21]$. This value was used in the calculation for estimation of arsenic exposure from the seaweed products analyzed. The average daily consumption depends on the culture and the geographical location. Indonesian population may consume lower amount of seaweed compared to that of Korea; hence, the exposure to arsenic from the intake of these seaweed products is lower.

Table 3. Estimated inorganic arsenic concentration in seaweed products analyzed.

\begin{tabular}{cccc}
\hline Sample & $\begin{array}{c}\text { Origin } \\
\text { Products }\end{array}$ & $\begin{array}{c}\text { Total arsenic } \\
\text { (mg/kg)* }\end{array}$ & $\begin{array}{c}\text { Inorganic arsenic } \\
\text { (mg/kg)* }\end{array}$ \\
\hline Catoni & Domestic & 0.86 & 0.028 \\
& A & $(0.79$ to 0.92$)$ & $(0.026$ to 0.030$)$ \\
Nori & Foreign & 17.20 & 0.57 \\
& B & $(14.62$ to 18.58$)$ & $(0.48$ to 0.61$)$ \\
& Foreign & 20.95 & 0.69 \\
& C & $(16.05$ to 30.14$)$ & $(0.53$ to 0.99$)$ \\
& Foreign & 20.15 & 0.66 \\
& D & $(18.81$ to 21.34$)$ & $(0.62$ to 0.70$)$ \\
& Foreign & 12.75 & 0.42 \\
& E & $(10.24$ to 15.12$)$ & $(0.34$ to 0.50$)$ \\
\hline
\end{tabular}

${ }^{*}$ Data are expressed as the average concentration (range minimum to maximum concentration) ( $\mathrm{mg} / \mathrm{kg}$ dry weight).

From the data obtained from the seaweed product analyzed, assuming that $8.5 \mathrm{~g}$ seaweed is ingested by a $60 \mathrm{~kg}$ individual per day, the estimated exposure to total arsenic from the seaweed products analyzed made up to $8.54 \%$ of the PTDI of total arsenic $(50 \mu \mathrm{g} / \mathrm{kg}$ bw per day). The estimated exposure to inorganic arsenic from the consumption of the seaweed products comprised $6.52 \%$ of the PTWI for inorganic arsenic which is $15 \mu \mathrm{g} / \mathrm{kg}$ bw (equaivalent to $2.1 \mu \mathrm{g} / \mathrm{kg}$ bw per day) [22].

Fig. 3 shows the estimated total arsenic daily intake from the consumption of $8.5 \mathrm{~g}$ of seaweed products per day by a $60 \mathrm{~kg}$ individual.

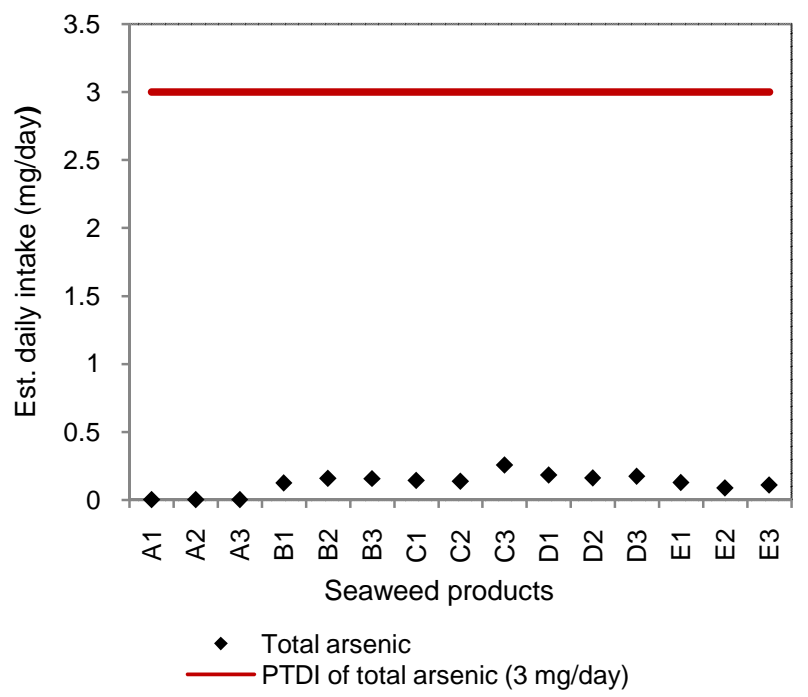

Fig. 3. Estimated total arsenic daily intake from the assumed consumption of seaweed products analyzed.

Fig. 4 shows the estimated inorganic arsenic intake from the consumption of seaweed products with the assumption that $8.5 \mathrm{~g}$ of seaweed products is consumed per day by a $60 \mathrm{~kg}$ individual.

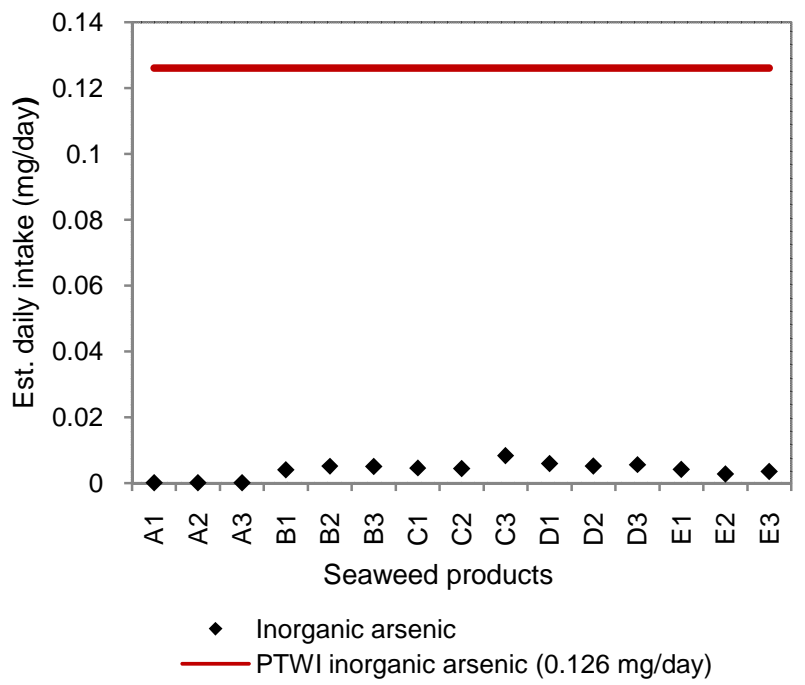

Fig. 4. Estimated inorganic arsenic daily intake from the assumed consumption of seaweed products analyzed.

The exposure to total arsenic and inorganic arsenic from the consumption of these seaweed products is still low compared to the PTDI and 
PTWI values established for total arsenic and inorganic arsenic, respectively. However, for the average daily intake of arsenic, the contribution of arsenic intake from other types of food should also be considered. Grains such as rice and wheat, vegetables, egg, meat and other seafood also contain arsenic in both inorganic and organic forms. Vegetables and cereals have the highest mean ratio of inorganic arsenic to total arsenic of $84 \%$ [19]. Typically, the Indonesian diet mainly consists of rice. The consumption of high amounts of seaweeds, especially those with high arsenic content, can increase the current exposure to total arsenic.

From the findings, it is advisable that to minimize the risk to the health of the consumers, products with high arsenic contents should be consumed only in moderation.

\section{CONCLUSION}

The total arsenic concentration in the catoni and nori types of seaweed food products was determined by validated neutron activation analysis (NAA) method to be in the range of 0.79 to 30.14 $\mathrm{mg} / \mathrm{kg}$ with analytical accuracy of $102.04 \%$ and analytical precision of $3.88 \%$. The highest concentration in products sold in the markets was found in nori from a foreign source while the lowest concentration was found in catoni seaweed. The estimated exposure to arsenic contributed by the analyzed products is from $0.07 \%$ to $8.54 \%$ of the provisional tolerable daily intake (PTDI) for total arsenic which is still far below the maximum tolerable level.

\section{ACKNOWLEDGMENT}

The authors would like to express their gratitude to the staff members in the Labelled Compound and Radiometry Division, Centre of Nuclear Technology for Materials and Radiometry, BATAN Bandung, especially Diah Dwiana Lestiani, Natalia Adventini, Syukria Kurniawati, Indah Kusmartini and Woro Yatu Niken Syahfitri for the help and guidance along this project.

\section{REFERENCES}

1. M. Caliceti, E. Argese, A. Sfriso and B. Pavoni, Chemosphere 47 (2002) 443.

2. J.H. Fitton, Alternative Complement Ther $\mathbf{9}$ (2003) 29.

3. C. Almela, M.J. Clemente, D. Velez and R. Montoro, Food Chem. Toxicol. (2006) 22.
4. M. Rose, J. Lewis, N. Langford, M. Baxter, S. Origgi and M. Barber, et al., Food Chem. Toxicol. 45 (2007) 1263.

5. G.F. Nordberg, B.A. Fowler, M. Nordberg and L. Friberg, Handbook on the toxicology of metals, 3rd ed., Academic Press, California (2007) 367.

6. B.G. Katzung, Basic and Clinical Pharmacology, 10th ed., McGraw-Hill Companies, Singapore (2007) 946.

7. R. Schoof, L. Yost, J. Eickhoff, E. Crecelius, D. Cragin and D. Meacher, Food Chem. Toxicol (1999) 839.

8. Anonymous, Toxiclological Profile for Arsenic, ATSDR (2007) 56.

9. J. Borak and H.D. Hosgood, Regul Toxicol. Pharmacol. 47 (2007) 204.

10. H. Castlehouse, C. Smith, A. Raab, A.A. Meharg and Feldmann, Environ. Sci. Technol. 37 (2003) 591.

11. W.D. Ehmann and D.E. Vance, Radiochemistry and Nuclear Analysis., John Wiley \& Sons, New York (1991) 255.

12. Anonymous, Evaluation of Certain Food Additives and Contaminants (thirty-third report of Joint FAO/WHO Expert Committee on Food Additives), Technical Report Series (776) WHO (1989).

13. R.R. Greenberg, P. Bode and E.A. De Nadai Fernandes, Spectrochim. Acta B 66 (2011) 280 .

14. K. Park, N. Kang, Talanta 73 (2007) 791.

15. Anonymous, Certificate of Analysis Standard Reference Material ${ }^{\circledR}$ 1566b Oyster Tissue, NIST (2011).

16. Anonymous, AOAC Guidelines for Single Laboratory Validation of Chemical Methods for Dietary Supplements and Botanicals. http://www.aoac.org. Retrieved in June (2012).

17. V. Devesa, D. Velez and R. Montoro, Food Chem. Toxicol. 46 (2008) 1.

18. Anonymous, SNI 7387:2009, Maximum Limit of Heavy Metal Contamination in Food. (in Indonesian). http://sisni.bsn.go.id. Retrieved in July (2012).

19. C. Uneyama, M. Toda, M. Yamamoto and K. Morikawa, Food Addit. Contam. 24 (2007) 447. 
20. Anonymous, The Third Korea National Health \& Nutrition Examination Survey (KNHANES III), Nutrition Survey (1). http://www.khidi.or.kr. Retrieved in August (2012).

21. Y.O. Hwang, S.G. Park, S.M. Choi and
M.Y. Kim, Food Addit. Contam. Part B 3 (2008) 293.

22. Anonymous, Joint FAO/WHO Expert Committee on Food Additives, 72nd meeting, JECFA/72/SC., WHO (2010). 